\section{Conflitos, assistência e redes de poder em torno da fundação da Santa Casa de Misericórdia de Campos dos Goytacazes, 1786-1795}

Conflicts, welfare, and power networks in the founding of Santa Casa de Misericórdia of Campos dos Goytacazes, 1786-1795

Claudia C. Azeredo Atallah ${ }^{i}$

i Professora, Departamento de História/ Universidade Federal Fluminense. Campos dos Goytacazes - RJ - Brasil orcid.org/0000-0001-5298-9939 clauatallah@gmail.com
ATALLAH, Claudia C. Azeredo. Conflitos, assistência e redes de poder em torno da fundação da Santa Casa de Misericórdia de Campos dos Goytacazes, 1786-1795. História, Ciências, Saúde-Manguinhos, Rio de Janeiro, v.26, supl., dez. 2019, p.179-194.

Resumo

O artigo propõe uma discussão a respeito da fundação da Santa Casa de Misericórdia de Campos dos Goytacazes e seus desdobramentos na sociedade local, além de um breve estudo sobre os dois primeiros provedores e suas redes (1792-1795). A instituição foi inaugurada em 1792, no auge das transformações ocorridas na Europa. Em Portugal, o intendente-geral da Polícia de dona Maria I, Diogo Inácio de Pina Manique, planejava reformas à frente da administração da saúde pública. Analisam-se, dentro desse contexto, as questões que motivaram a instalação da referida Misericórdia e suas relações com as dinâmicas sociais e políticas típicas de Antigo Regime, ainda enraizadas na sociedade colonial e que adentrariam o século XIX.

Palavras-chave: assistência; redes; Antigo Regime.

Abstract

A discussion is proposed concerning the founding of Santa Casa de Misericórdia of Campos dos Goytacazes and its ramifications in local society, as well as a brief study of its first two directors and their networks (1792-1795). The institution was opened in 1792 at the height of upheavals in Europe. In Portugal, the chief of police under Maria I, Diogo Inácio de Pina Manique, planned reforms for the public health administration. An analysis is proposed of the issues that motivated the founding of said institution and how it related to the social and political dynamics typical of the ancien régime, which were still deep-rooted in colonial society, and which remained intact into the nineteenth century.

Keywords: welfare; networks; ancien régime. 


\section{Pobreza e assistência na Europa}

A preocupação com a pobreza precede a época moderna. Durante o século XIII, as confrarias, surgidas no contexto das pestes e da migração para as cidades, foram formadas por religiosos e cidadãos leigos preocupados com a caridade para com os mais pobres e, principalmente, o bem-estar dos seus pares e suas famílias. Segundo A.J.R. Russell-Wood (1981, p.3), "em nenhum lugar as irmandades fundadas para fins caritativos se multiplicaram tão profusamente quanto na Itália do norte e central". As exigências imprescindíveis para a admissão nessas instituições estavam resumidas à propagação da fé católica e ao cultivo da boa reputação.

Em Portugal não foi diferente. Fome, guerras e doenças se alastraram por toda a Europa e assolaram o reino durante a baixa Idade Média, sobretudo com o retorno dos cruzados e as invasões mouriscas. Da mesma forma, a expansão marítima, orquestrada durante o século $\mathrm{XV}$, colaborou com o quadro de desequilíbrio social ao incentivar o despovoamento agrário e o abandono da previsibilidade de subsistência. Nesse caos social, as hospedarias, que, segundo Russel-Wood (1981), por vezes apresentavam uma "natureza ambivalente" ao funcionar também como hospitais, espalharam-se pelos caminhos que ligavam o norte ao sul e abrigavam andarilhos exaustos ou que adoeciam por suas andanças. A partir do século XVI, a Coroa portuguesa começou a se preocupar com a expansão da jurisdição dessas associações. Tal aspecto inspirou a busca por estratégias que reduzissem suas esferas de atuação, enquanto as misericórdias cresciam em quantidade, riqueza de seu patrimônio e número de assistidos e irmãos associados. Panorama que, durante os dois próximos séculos, só veio a se intensificar, especialmente devido à complexidade das relações de interdependência entre os confrades e a monarquia ${ }^{1}$ (Russell-Wood, 1981; Sá, Paiva, 2002, p.7).

O século XVIII trouxe mudanças significativas para a população europeia. No tocante às questões assistencialistas, essa foi uma época em que aflorou uma consciência cidadã que transformaria preocupações com a pobreza dos mais carentes em dever social sob a égide das ideias racionalistas. A filantropia, que incorporou as preocupações cristãs da caridade e, para além daí, associava-as à utilidade social, possuía um caráter essencialmente laico. Essa deveria ser uma ação intervencionista e transformadora, nos moldes das sociedades estruturadas nos valores da razão e da justiça preconizadas pelo iluminismo. Anteriormente, a caridade movida pela cultura da fé e assentada nas escrituras justificava e auxiliava a normatização das regras de obediência religiosa. Mais ainda, a sociedade de Antigo Regime, edificada sobre hierarquias e privilégios, via-se atrelada a esses princípios para garantir à elite sua posição de mantenedora e benfeitora social (Subtil, 2015; Sá, 2013, p.9). No entanto, os ares da razão iluminista impunham outros rumos à prática assistencialista: a filantropia.

Na Europa do norte, devido à industrialização dos meios de produção e, consequentemente, à banalização da mão de obra, a miserabilidade do ser humano tornava-se menos velada. As cidades, repletas de contrastes, refletiam o quanto o desenvolvimento urbano e industrial havia sido determinante para o aprofundamento das diferenças sociais. A urgência das práticas assistencialistas se tornava um dever cívico e virtuoso, adquirindo influência direta na sociedade e em seu desenvolvimento. Tornava-se, a partir daquele contexto, uma questão de saúde pública (Gonçalves, 2009, p.11). 
Em Portugal e em seus domínios, durante a segunda metade do século XVIII, a ideia de higienização (inclusive social) esteve na ordem do cotidiano e era ditada principalmente pela preocupação com o aumento da população, em particular a colonial. Esse panorama ganhou estrutura com as reformas pombalinas e, sobremaneira, a partir da instalação da Intendência-geral da Polícia, em 1760. Durante o reinado de dona Maria I, o intendentegeral da Polícia, Diogo Inácio de Pina Manique, seria responsável pelo desenvolvimento de uma ciência da polícia, ao mesmo tempo que planejava um fortalecimento do centro do poder em detrimento dos poderes municipais (Subtil, 2013, 2015).

Laurinda Abreu desenvolveu importante análise acerca do tema em seu estudo sobre a Intendência da Polícia de Pina Manique. Segundo a autora, algumas das mais importantes tentativas de reformas no campo assistencial e de saúde pública do Estado monárquico português aconteceram sob esse comando. No entanto, em que pese seus esforços, o intendente da rainha não foi capaz de modernizar a assistência, muito menos criar um modelo que perdurasse para as gerações que o seguiram. A precariedade da administração pública em Portugal e o problemático panorama econômico da época, bem como os constantes embates com as poderosas ordens religiosas e todo o seu patrimônio, desestruturaram as intenções reformistas de Pina Manique. Ainda há que considerar as intricadas redes de poder que tornavam as relações de interdependência essenciais. Fazia-se necessário, naquela conjuntura, "estar no centro da decisão política para que os projetos avançassem" ou ao menos pertencer às redes que perpassavam a administração política. $\mathrm{E}$ o intendente se isolaria cada vez mais (Abreu, 2013, p.432).

Maria Antónia Lopes ressaltou que essa foi uma época de grandes dificuldades para as misericórdias portuguesas, afetadas, durante a transição do século XVIII para o XIX, ainda que indiretamente, por diversos fatores. A exaustão aurífera nas minas, as guerras europeias e mais tarde a invasão francesa alarmaram as estruturas portuguesas, sociais, políticas e econômicas. Notadamente, o ocaso de uma nobreza acometida pelo marquês de Pombal durante seu ministério se refletia na inadimplência de suas dívidas com as misericórdias, que, além de lugares privilegiados de ascensão social, eram também suas credoras. "As Misericórdias empobrecidas tornaram-se pouco prestigiantes" e, por isso, perderam a importância para essas elites. O desinteresse administrativo, aliado às preocupações sociais desses grupos gravemente afetados pela conjuntura da época, foi responsável pela redução das práticas assistencialistas (Lopes, 2002, p.80).

O fim dos Setecentos foi deveras complexo para tais instituições. Segundo Renato Franco (2014, p.12), "no século XVIII, a criação de uma Misericórdia já não gozava do tom eufórico" dos séculos anteriores, tom relacionado à "rápida confirmação de privilégios" de outrora. Desde sua estruturação, foram instaladas confrarias de misericórdias por todo o império português. Essas instituições tendiam a se integrar às dinâmicas locais e com o tempo passaram a atender às demandas sociais, tanto de assistência quanto as relativas à acensão social de seus membros. Apesar de guardarem semelhanças, as misericórdias da América portuguesa, à exceção das do Rio de Janeiro e de Salvador, eram bastante diferentes no tocante às ações e simbologias de suas congêneres portuguesas.

A Santa Casa de Misericórdia do Rio de Janeiro, ao que parece, apresentou um crescimento ao longo do século XVIII, caminhando, assim, conforme sugere Renato Franco 
(2011, p.175), na "contramão" de suas "congêneres setecentistas". A virada do século XVIII para o XIX é marcada pela presença de homens de grosso trato entre seus confrades. O autor os caracteriza "como uma espécie de grupo à parte" que dominou os principais lugares de controle nos meandros dessa instituição, alternando e até disputando posições com importantes figuras do poder local. Alguns dos principais comerciantes da praça do Rio de Janeiro chegaram à posição de primeiro foro.

A cidade do Rio de Janeiro passaria, ao longo do século XVIII, por um profundo alargamento demográfico. Sua centralidade imperial, de caráter político e econômico, tornou-a um dos principais destinos para estrangeiros e portugueses pobres que buscavam oportunidades em terras coloniais (Bicalho, 2003; Fragoso, 1992). Com a intensificação da dinâmica mercantil e a complexidade das relações sociais, associadas à insalubridade das ruas e moradias, a pobreza agravou, exigindo maior estrutura das instituições assistencialistas na cidade imperial. Ao longo da centúria, a Santa Casa de Misericórdia fluminense tratou de se adequar ao panorama que se anunciava: novas instalações foram criadas, como a roda de expostos e o acolhimento das órfãs. Segundo Renato Franco (2011, p.113), "essa evolução no quadro assistencial" não teria como razão primordial o atendimento às "demandas sociais", mas o crescente cosmopolitismo que marcava o aumento da "capacidade financeira das elites" (renovada pela inserção de comerciantes), bem como a "importância social" adquirida pela cidade.

Nesse contexto de ressignificações das instituições de assistência que embala o final do século XVIII no reino e em seus domínios, foi fundada, em 1792, a Santa Casa de Misericórdia da capitania da Paraíba do Sul dos Campos dos Goytacazes, por provisão régia de dona Maria I (Lamego, 1913-1943, p.158).

A instituição campista veio atender a uma demanda regional provocada pelo aumento da pobreza, devido principalmente ao fluxo humano que se intenficou nos caminhos entre o Rio de Janeiro e os sertões do norte, conforme veremos abaixo. Em paralelo a essas transformações no âmbito da assistência pública e das novas diretrizes apontadas a partir daí, o estudo do estabelecimento da Misericórdia da Paraíba do Sul também nos sugere circunstâncias comprometidas, em sua essência, com as relações de poder mantenedoras das hierarquias. Essa dinâmica se pautava na cultura política de Antigo Regime, que embasava uma configuração hierárquica e demarcadora de diferenças qualificadoras dos grupos constitutivos do espaço social. Em uma sociedade juridicamente desigual, as redes organizadas entre as elites eram fundamentais para o estabelecimento das relações de interdependência (Xavier, Hespanha, 1994; Monteiro, 1996; Duby, 1994).

Sobre esse aspecto, é importante demarcar o quanto a razão substanciadora do estabelecimento das misericórdias quinhentistas estaria presente, em linhas gerais, em suas congêneres coloniais. A simbiose entre a "chancela política" a certas localidades e a ereção das santas casas marcou demasiadamente, segundo Renato Franco (2011, p.107), os dois primeiros séculos da América portuguesa. Pretendo, a partir das linhas abaixo, demonstrar que a fundação da Santa Casa de Misericórdia de Campos dos Goytacazes, no final do século XVIII, atendeu a essa dinâmica. 


\section{A capitania da Paraíba do Sul dos Campos dos Goytacazes: o crescimento econômico e a fundação da Misericórdia}

Paraíba do Sul dos Campos dos Goytacazes ou Campos dos Goytacazes eram expressões que, até início dos Oitocentos, faziam menção a uma vasta área, compreendendo, administrativamente, a capitania da Paraíba do Sul. Apesar de distante dos dois principais centros urbanos da então América portuguesa, Rio de Janeiro e Salvador, a região era considerada estratégica para a economia regional e, principalmente, para chegar às minas auríferas dos sertões de Macacu (Faria, 1998, p.27).

Lendariamente, terra de gentio bravo e devorador de carne humana, os invencíveis goitacazes. Historicamente, capitania doada pela Coroa portuguesa a Salvador Correia de Sá e Benevides por serviços prestados no sul da América portuguesa e no oeste da África. Em 1764, seu primogênito, o primeiro visconde de Asseca, Martin Correia de Sá e Benevides Velasco, tomava posse da donataria em seu nome (Boxer, 1973). Em 1754, após décadas de conflitos entre os donatários e os moradores da região, a capitania passou a integrar o patrimônio da Coroa portuguesa. ${ }^{2}$

A partir da segunda metade do século XVIII, o panorama político tendeu a se estabilizar. Os moradores da Paraíba do Sul, após os conflitos por terras e por poder que atingiram a região durante quase um século, alcançaram uma estabilidade que os favoreceria política e economicamente, sobretudo no contexto colonial. A capitania se tornou um grande atrativo para homens e para o capital. Na economia, a pecuária cedeu espaço para os primeiros engenhos de açúcar, que se multiplicaram a partir do final do século XVIII (Faria, 1998, p.32).

Há, no entanto, que se ressaltar o caráter lento e gradativo dessa transição para a economia açucareira. Em 1785, Manoel Martins do Couto Reis (2011), em sua "Descrição Geográfica, Política e Cronográfica do Distrito dos Campos dos Goytacazes", destacava a importância da criação de gado para a região. A planície servia também como passagem e parada para "as boiadas" oriundas do sul da colônia, por vias terrestres e marítimas. O capitão ainda mencionou certa precariedade em torno da agricultura da capitania: "A falta de arte nos seus lavradores, o desprezo com que são atendidos os seus requerimentos, o nenhum favor que recebem das justiças de dentro do País; a pouca estimação que se faz deles, é a origem de se não ver nela maiores progressos" (p.112).

No contexto das transformações observadas a partir da incorporação da capitania pela Coroa no final do século XVIII, a pecuária representava uma parte bastante significativa da economia regional. $\mathrm{O}$ avanço da lavoura açucareira também foi inegável. Couto Reis (2011, p.112) registrou que, durante a primeira década do século XIX, a região contava com 133 engenhos em produção de açúcar e aguardente, e 12.085 escravos. "Quase nenhum gado era exportado. O mercado interno incumbia-se de receber toda a produção". Sheila de Castro Faria (1998, p.33) observou que, na Paraíba do Sul, apesar de o açúcar ter se tornado a mola mestra da economia regional e local, algumas áreas de baixa produtividade para os canaviais mantiveram seus pastos.

A mudança da capital de Salvador para o Rio de Janeiro em 1763, a queda na produção do açúcar no recôncavo da Guanabara (o que acabou por liberar investimentos para outras 
regiões), bem como as transformações operadas com a extração aurífera, colaboraram para fazer da Paraíba do Sul um dos principais centros urbanos de toda a colônia. A expulsão dos jesuítas em 1759 ocasionou uma grande disponibilidade de terras na região. Adquiridas em leilões, essas terras se transformariam em canaviais abastecedores de todo o centro-sul. A partir do início do século XIX, a capitania se tornou a principal fornecedora de açúcar para o Rio de Janeiro e Minas Gerais (Faria, 1998, p.33).

Tal panorama proporcionou o fortalecimento da elite local. Eram homens que ascenderam econômica e socialmente, descendentes dos primeiros conquistadores daquelas terras que se valeram de mercês e privilégios concedidos pela monarquia em troca de fidelidade e do fortalecimento dos laços de vassalagem. ${ }^{3}$ Homens que tiveram conflitos com os asseca por terras, jurisdição e poder. Ainda há que considerar aqueles que enriqueceram com o recrudescimento das relações econômicas no final do século XVIII no centro-sul da América portuguesa, sobretudo comerciantes de grosso trato que acumularam fortunas com o comércio entre as capitanias.

Em 1791, o vice-rei conde de Resende ordenara ao tenente-coronel José Thomaz Brum que fosse à vila de São Salvador com o objetivo de acalmar os ânimos exaltados pelos conflitos entre os "filhos da terra" e os forasteiros, comerciantes portugueses que chegaram à Paraíba do Sul buscando oportunidade de negócios e enriquecimento (Lamego, 1951, p.131). As contendas giravam em torno de denúncia de propinas, do fato de que os referidos negociantes teriam "subornado as justiças com oferecimentos consideráveis e também com o respeito dos poderosos" (Carta..., 1868, p.168). Mais profundamente, tal panorama possuía relações intrínsecas com as redefinições pelas quais a sociedade de Antigo Regime passava em fins dos Setencentos. Os homens de grosso trato circulavam com mais estabilidade por todo o império português, estabelecendo redes mercantis e clientelares, ${ }^{4}$ em busca de enriquecimento e ainda almejando enobrecer.

Todo esse processo aumentou o número de pessoas que nada tinham de seu. A estabilidade que a posse da terra oferecia, por gerações, às elites locais havia sido intensamente abalada. O homem pobre do final do século XVIII na Paraíba do Sul não se fixava muito tempo "num mesmo lugar" e era usualmente preto ou pardo. Compunha uma leva de "marginais" e "andarilhos" que engrossavam a mão de obra disponível. Quando autônomo, passava a significar, para aquela sociedade comandada pelos homens bons da região, uma ameaça à hierarquização social costumeira (Faria, 1998, p.109).

Esse contexto de transição e estabilização econômica, de surgimento de novas preocupações no âmbito social, portanto, é o ambiente para a fundação da Santa Casa de Misericórdia de Campos dos Goytacazes em 1792.

Sua instituição tem origem vinculada à Irmandade de Nossa Senhora Mãe dos Homens, reunida em 1786 por alguns desses homens bons da capitania. Com sede inicial na igreja matriz, nesse mesmo ano se iniciou a construção da igreja de Nossa Senhora Mãe dos Homens, pertencente à mesma irmandade, em um terreno cedido pela Câmara da vila de São Salvador. A obra foi concluída em 1790, após embargo devido a alguns problemas estruturais. Em 25 de julho de 1790, os irmãos se reuniram para firmar compromisso, registrado em ata, que só seria aprovado por dona Maria I em 5 de julho de 1791. Como provedor foi nomeado o capitão Manuel Francisco de Azevedo Castelão (Ata..., 5 abr. 1812). 
Havia um hospital anexo simples, "casinha de pau a pique", com poucos leitos. No fundo da igreja foi instalado o cemitério (Lamego, 1951, p.13).

A recém-criada instituição contava com procurador letrado, o licenciado João Leite da Silva, e com um cirurgião-mor do Terço da infantaria para o hospital, José Luiz Monteiro de Souza, que devia visitar os enfermos "todos os dias de manhã e de tarde e quando mais for preciso". Ao procurador cabia cuidar das "causas e dependências pertencentes à Santa Casa, como para cuidar no livramento dos presos pobres da cadeia" da vila de São Salvador (Ata..., 1979a, p.327).

De acordo com a regra, a Misericórdia de Campos dos Goytacazes só seria reconhecida a partir da aprovação de seu compromisso pela rainha dona Maria I. Conforme citado, a provisão de sua confirmação foi afixada na Câmara da vila de São Salvador em 21 de dezembro de 1792. A decisão régia garantia à Santa Casa de Campos as mesmas isenções, graças e regalias permitidas à do Rio de Janeiro (Lamego, 1913-1943, p.158).

Em 18 de março de 1790, o padre Manoel Pereira Motta, que servia de capelão, recusouse a continuar em seu cargo. Alegava o fato de não poder concordar com as providências "sem o beneplácito de Sua. Exa. Reverendíssima, pelo cumpra-se seu no compromisso que V. M. obtiveram de Sua Majestade, não posso cumprir os meus deveres, sendo seu capelão" (Ata..., 5 abr. 1812).

Tendo em vista a recusa de Pereira Motta, a mesa elegeu o padre José Joaquim de Araújo como capelão da referida Santa Casa. Após o aceite, o religioso concordou em "celebrar em todos os sábados, domingos e dias santos ... missa, às horas que fossem conveniente por todos os irmãos vivos e defuntos; acompanhar a irmandade em todos os atos de enterros e procissões, encomendando a ladainha e mais orações nos ditos sábados; e em todas as funções que mais houverem nesta Santa Casa e ella ordenar" (Ata..., 5 abr. 1812).

Como se vê, o reconhecimento real se fazia fundamental para a legitimidade da instituição perante a sociedade local. Às relações costumeiras, sobrepunham-se diretrizes reais. Importante ressaltar que, ainda que a confirmação régia fosse regra, as elites locais se achavam, em especial nas paragens coloniais de Antigo Regime, imbuídas de representatividade real, e tal aspecto pode ter influenciado os debates em torno da espera desse ato para os irmãos da Boa Morte. E, como veremos a seguir, tal aspecto causaria malestar junto à elite local em mais de uma ocasião.

Em 20 de janeiro de 1790, junto às comemorações do dia de São Sebastião organizadas pela Câmara municipal da vila de São Salvador, Manuel Fonseca de Azevedo Castelão, protetor da Irmandade de N.S. Mãe dos Homens, teria causado "um grande conflito ... pelas quatro horas da tarde, por ocasião da saída da procisão". Reclamava o direito de sua irmandade de preceder as demais, mais antigas e já confirmadas pelo reino, no cortejo em homenagem ao santo. Em defesa de seu pleito, o capitão Azevedo Castelão alegava ser a Nossa Senhora Mãe dos Homens a única irmandade de brancos na capitania da Paraíba do Sul, "chamando de bodes e negros os irmãos Benedito, Rosário, Boa Morte e Terço". Na tentativa de elucidar o conflito, o vigário Bartholomeu Martins da Motta suspendeu tal festividade (Certidão..., 1913-1943, p.154).

Pelos idos do mesmo ano, por ocasião das comemorações de Corpus Christi, o imbróglio se repetiria. A Câmara de São Salvador, prevendo o incidente, mandara afixar um edital 
que ordenava às irmandades utilizarem "de suas precedências, conforme o costume e posse em que estavam". O vigário da vara, Manuel Pereira da Motta, constatando que a recomendação da municipalidade não surtira efeito e com o objetivo de neutralizar o iminente conflito armado na praça da matriz de São Salvador, ordenou que seguissem "as cruzes das irmandades, com seus respectivos corpos, pondo-se em seus lugares na rua" (Atestado..., 1913-1943b, p.155).

Perante a recusa dos irmãos da Nossa Senhora Mãe dos Homens em seguir as irmandades mais antigas, e com o apoio da Câmara e de alguns homens bons da vila, a contenda foi levada à alçada do vice-rei, José Luis de Castro, que emitiu a seguinte resolução: "Primeiramente tem preferência a tudo a Irmandade do Santísismo Sacramento e depois as Irmandades de N. S. e a estas se devem seguir todas as outras, conforme as suas antiguidades e privilégios, e quando me venha a constar ser alterada esta regularidade, castigarei severamente aqueles que influam em semelhante desordem" (Atestado..., 1913-1943b, p.155).

O vice-rei confirmava a prerrogativa das irmandades de brancos, entre elas as vinculadas às santas casas. Conflitos como esse possuem relações intrínsecas com o caráter da sociedade de Antigo Regime, profundamente matizada pelas hierarquias sociais e pela religiosidade. Tais instituições possuíam um papel preponderante em todo esse universo sociocultural.

Costumeiras nas sociedades tardomedievais, as irmandades exprimiam muito bem o universo sociocultural daquela época. Leigas e voltadas para a prática da caridade pública, tais instituições exerciam também um papel agregador, coadunando interesses religiosos e culturais à necessidade de demarcação de espaços sociais em uma sociedade juridicamente hierarquizada. Nesse contexto, as irmandades de pretos e pardos possuíam uma grande importância, principalmente na América portuguesa, pois expressavam formas de entrelaçamentos de crenças e práticas vivenciadas no mundo colonial. "Representavam também uma das poucas - senão a única - formas de associação permitidas à população de cor" naquelas terras (Boschi, 1986, 1998, p.422).

Ainda há que considerar a existência de hierarquias entre essas irmandades. As irmandades do Rosário instaladas em terras luso-americanas recebiam privilégios da Coroa e da Igreja católica que as demais irmandades de pretos e pardos não alcançavam, sobretudo por funcionar como um "instrumento de conversão dos africanos escravizados", isso ainda no século XVI. Os irmãos da Boa Morte, geralmente pardos, não admitiam em seus compromissos a associação de negros escravizados ou forros, e até mesmo a participação de brancos era minuciosamente acompanhada pelos conselheiros e diretores. Ainda assim, a entrada de membros da elite branca para posições como escrivão, tesoureiro ou procurador era quase uma regra devido à necessidade de letramento (Karasch, 2010, p.262).

Na Paraíba do Sul, as irmandades da Boa Morte e de São Benedito se instalaram ainda na primeira metade do século XVIII. Em 1736, a Boa Morte recebia sesmaria da Câmara da vila de São Salvador, "para fazerem sua Igreja", isentos de foro "ou tributo algum". A capela deveria ser erigida "dentro de um ano, e não o fazendo ... [se tornariam] devolutas". A concessão havia se dado da mesma forma para a irmandade de São Benedito, anos antes... (Ata..., 1979b, p.162).

Um cemitério foi instalado no fundo da capela da irmandade em 1792, benzido pelo capelão José Joaquim de Araújo. No mesmo ano, foi fundada a Funerária Santa Casa, que 
possuía a função de realizar os enterramentos não só dos irmãos e dos pacientes internados no hospital, mas de todos aqueles que fossem considerados necessitados. Ao que parece, segundo um atestado emitido pelo cirurgião-mor, a enfermidade e a morte de miseráveis na capitania da Paraíba do Sul, como em diversas paragens naquela época, eram problemas recorrentes e causavam constrangimentos constantes aos poderes instituídos. A intenção era demarcar a importância que a instituição da Santa Casa de Misericórdia possuía para a região. Monteiro de Sousa atestava ser "público e notório, e eu sou testemunha ocular, terem morrido muitas pessoas pobres de necessidade por falta de todo o socorro humano, ainda dentro desta vila, antes da ereção da expedida Santa Casa. Também tenho observado que depois da referida ereção, não tenho visto corpos rolando pelo átrio da Matriz, sem os darem à sepultura, com geral escândalo da piedade cristã" (Atestado..., 1913-1943a, p.160).

Russel-Wood (1981, p.153) já havia chamado atenção para o quanto eram complexas as questões relativas aos funerais e enterros na época moderna. Revela-nos que, desde a Antiguidade, tais questões integravam as preocupações das irmandades, fundadoras de uma "tradição de funerais cooperativos" que rompeu gerações. Os compromissos dessas associações previam a assistência aos irmãos e a todos que não reuniam condições de arcar com o ônus dos enterramentos.

Em 1793, a Santa Casa de Misericórdia de Campos é oficialmente inaugurada com a eleição de seu primeiro provedor, o mestre de campo José Caetano Barcellos Coutinho. Figura importante regionalmente, Barcellos Coutinho era membro de uma das mais importantes famílias da região da Paraíba do Sul (Lamego, 1951, p.13).

Charles Boxer (1969), em importante trabalho sobre o império marítimo português, afirmou que as câmaras e as misericórdias constituíam "pilares gêmeos" da sociedade colonial. Nessas instituições, quase sempre estavam reunidos os principais senhores da terra que assumiam o papel de elites nas distantes paragens coloniais. Nesse contexto, a dinâmica administrativa local foi transferida para as mãos desses homens que ordenavam também as relações sociais. Segundo Boxer, tal panorama garantia "uma continuidade que governadores, bispos e magistrados passageiros não podiam assegurar" (p.263).

Durante o Antigo Regime português, as relações de poder se constituíam em bases para a administração, e tal configuração viabilizava o governo a distância. Em um beneplácito ao movimento de seus vassalos pelo Atlântico e reconhecendo a importância deles para a máquina propulsora que fazia o império português funcionar, a monarquia abriu mão da centralização, de outro modo inviável, em prol da manutenção de seus domínios. Dessa forma, configurou-se um emaranhado de redes clientelares que unia homens e instituições entre si, criando uma relação que interligava todo o império e configurava sua estrutura administrativa (Xavier, Hespanha, 1994).

Ainda que em fins do século XVIII, quando as estruturas mentais e políticas acabavam de passar por transformações advindas dos movimentos franceses reverberados no mundo colonial, essas relações de poder perduravam nas estruturas da política administrativa imperial portuguesa.

Na Paraíba do Sul não seria diferente. A partir de 1792, importantes nomes da região se alternaram ou se dividiram entre a Câmara e a Misericórdia. Além disso, alguns oficiais 
régios nomeados pelo rei também almejaram, estrategicamente, o cargo de provedor da Santa Casa. Por aqueles rincões coloniais, essa dinâmica representou, àquela altura, o cerne da lógica de Antigo Regime que pairava há séculos naquela sociedade imperial.

\section{Perfil dos dois primeiros provedores: conflitos, relações de poder e redes clientelares (1792-1795)}

Para concluir, será apresentado um estudo sobre o perfil dos dois primeiros provedores da instituição estudada. A intenção é demonstrar, ainda que de maneira geral, a importância local e regional desses homens e seus arranjos políticos e sociais na busca de lugares que garantissem suas permanências nessas tramas do poder local. Tramas que, não raras vezes, alcançavam outras partes do império português.

O primeiro provedor da Santa Casa de Misericórdia de Campos dos Goytacazes foi José Caetano Barcellos Coutinho. Membro de uma das famílias mais importantes daquela região, herdou em 1785 um suntuoso engenho de açúcar localizado em Quissamã, freguesia de Nossa Senhora de Capivary. Sua ascendência remontava ao século XVII e aos sete capitães desbravadores que receberam o privilégio de conquistar e povoar aqueles sertões da Paraíba do Sul, antiga capitania de São Tomé, em nome do rei (Soares, 2003).

Iniciou a carreira militar em 1779, ao substituir seu pai, João José de Barcelos, no ofício de mestre de campo de Campos dos Goytacazes. Mais tarde, em 1797, assumiu o então recém-criado Regimento de Milícias como coronel da mesma capitania. Escrevendo sobre sua morte, ocorrida em 1814, José Carneiro da Silva $(1819$, p.119) afirmou que o oficial "havia comandado os Campos dos Goytacases pelo espaço de trinta anos". Possuía, segundo o autor, "um caráter firme", conseguindo sempre a estima de "seus superiores".

Alguns documentos existentes no Arquivo Histórico Ultramarino, no entanto, sugerem cenário bem diferente. Queixas ao Conselho Ultramarino registraram conflitos que envolviam Barcellos Coutinho. Em 1786, Manoel Sebastião Vitorino da Silva e Melo solicitava à rainha, dona Maria I, nomear o então ouvidor da comarca como juiz em primeira instância "nas causas intentadas" contra José Caetano Barcellos Coutinho no Tribunal da Relação do Rio de Janeiro. O pedido se justificava, segundo seu autor, pelo receio que possuía "em apresentar os seus agravos junto dos juízes ordinários por serem apoiantes do suplicado" (Requerimento..., 1796).

No final da década de 1790, foi novamente acusado de parcialidades, de agir de forma imperativa e de ser um "transgressor" das leis do reino. O capitão-mor das Ordenanças da vila de São Salvador, José Francisco da Cruz, atribuía ao referido oficial o controle de uma rede muito bem estabelecida para "satisfações de suas paixões e dos muitos parentes e amigos congregados no partido do seu séquito ... que governam aqueles povos debaixo do seu nome". Todos os desmandos e imbróglios causados pelo militar, segundo a denúncia feita pelo capitão-mor, eram justificados pela "grande amizade" que o coronel dizia nutrir com o vice-rei, José Luis de Castro, o conde de Resende (Ofício..., 1799).

Devido à fragmentação documental, não foi possível conhecer a conclusão dessas denúncias. Sabe-se que Barcellos Coutinho recebeu apoio do conde de Resende em um oficio enviado pelo vice-rei ao Conselho Ultramarino em 1800 (Ofício..., 1800). 
Concomitantemente, o coronel do Regimento de Milícias solicitou à rainha "foro de fidalgo da Casa Real, bem como dois hábitos de Avis, para si e seu filho único". Em 1802, insistia em "remuneração por seus serviços e de seu pai" ao solicitar, dessa vez ao príncipe regente dom João, "a mercê do hábito da Ordem de Cristo, com uma comenda da mesma Ordem em Santo Eusébio de Aguiar de Beira ou Santa Maria de Pereiro ou outra qualquer". Há registros da concessão do hábito de Cristo a seu filho primogênito, João Antônio de Barcellos Coutinho (Requerimento..., 1802, 1801, 1796).

O segundo provedor, o ouvidor José Pinto Ribeiro, esteve à frente da Santa Casa de Misericórdia de Campos dos Goytacazes de 1794 a 1795. Nascido entre 1757 e 1758, era natural do Espírito Santo e descendia "das principais pessoas daquela capitania", tendo seus ascendentes exercido "os cargos da República". Bacharel em leis pela Universidade de Coimbra, Pinto Ribeiro habilitou-se pelo Desembargo do Paço em 1783, com excelentes referências em seus registros de admissão, à leitura de bacharel. ${ }^{5}$ Em 1784, foi nomeado juiz de fora em Benavente, Belmonte e Sortelha para um período trienal: uma primeira nomeação para juiz de fora era comum e demarcava o início da carreira de um oficial da justiça a serviço da monarquia (Leitura..., 1783).

Talvez por sua ascendência e sua consequente bem-sucedida leitura de bacharel, Pinto Ribeiro recebeu nomeação para desembargador da Bahia em 1800 e, a partir de 1807, terminaria sua carreira como desembargador da Relação do Porto, ápice da ascensão de um magistrado naquela época. Antes disso, porém, fora designado ouvidor-geral do Espírito Santo, por decreto de 22 de agosto de 1789 (Subtil, 2010, p.374).

A Ouvidoria Geral do Espírito Santo foi criada em 1732, com jurisdição sobre as vilas de Vitória, Guarapari, São Salvador dos Campos dos Goytacazes e São João da Praia, sendo as duas últimas pertencentes à capitania da Paraíba do Sul dos Campos dos Goytacazes. Entretanto, a comarca de Vitória seria criada apenas em 1741 a partir de um ato régio, e o primeiro ouvidorgeral do Espírito Santo, o bacharel Pascoal Ferreira de Veras, tomaria posse logo depois, ainda no mesmo ano (Atallah, 2017a, p.227). Somente em 1833 foi criada a comarca de Campos, e em 28 de março de 1835, a vila de São Salvador foi elevada à categoria de cidade da província do Rio de Janeiro, com o nome de Campos dos Goytacazes (Oliveira, 1975, p.207).

A comarca sob a responsabilidade de Pinto Ribeiro se estendia, portanto, até a Paraíba do Sul. Em terras goytacazes, o recém-nomeado ouvidor se viu às voltas com comerciantes de grosso trato que, em fins do século XVIII, chegavam à região constantemente, conforme já citado. Tal panorama tornava as relações sociais e políticas ainda mais frágeis naquela capitania. Da mesma forma, favorecia a associação entre homens importantes, que tinham como objetivo se resguardar e conservar suas posições estratégicas na localidade e perante o reino.

Quando em correição naquelas terras, José Pinto Ribeiro era acusado de cometer arbitrariedades e de favorecer alguns homens bons, aos quais esperava se associar em busca de segurança e prerrogativas na sociedade local. Nutria interesse em ocupar o cargo de provedor da Santa Casa de Misericórdia da região. Para tal, envolveu-se em uma intrincada rede de negociação e favorecimento que previa o casamento de sua sobrinha com um dos mais poderosos homens do poder local, Custódio Valentim Codeço. Em 1794, Pinto Ribeiro o agraciou com o cargo de procurador da Câmara da vila de São Salvador e logo depois o alocou no lugar de juiz ordinário (Representação..., 1794). Consoante ao provérbio 
alentejano referenciado por Charles Boxer (1969, p.275), "quem não está na Câmara está na Misericórdia", o ouvidor buscava presença em ambas as instituições, ainda que por vias clientelares.

Alguns outros homens importantes da região foram envolvidos nessa rede, casando-se com moças oriundas da família capixaba Pinto Ribeiro e sendo também agraciados com cargos camarários. No mesmo período, o ouvidor assumiu o tão almejado cargo na Santa Casa da Paraíba do Sul dos Campos dos Goytacazes, com o apoio irrestrito da Câmara da vila de São Salvador (Lamego, 1951, p.14).

João Pinto Ribeiro, tal como o primeiro provedor, envolvera-se em alguns conflitos nos rincões da Paraíba do Sul e, em 1796, também fora denunciado ao Conselho Ultramarino por "procedimentos impróprios" e por "exercer o cargo com irmãos, primos, cunhados e infinitos parentes e amigos" (Carta..., 1796). Dois anos depois, Pinto Ribeiro escreveu à rainha denunciando um atentado sofrido, em fins de sua provedoria, na ocasião dos festejos das santas virgens, no dia 21 de outubro de 1794. Contendas como essas eram comuns no universo político do Antigo Regime e possuíam profundas relações com a fragilidade das instituições administrativas do império português. As indefinições jurisdicionais dos corpos políticos tornavam as relações entre seus representantes extremamente frágeis e precárias. Por outro lado, esse panorama garantia a centralidade régia da monarquia, que assumia a posição de arbítrio e de referência de poder, garantindo assim a governança em seu nome (Lara, 2006, p.59; Gouvêa, 2010, p.167).

Apesar dos conflitos locais nos quais se envolveram e das denúncias impetradas contra eles, os dois primeiros provedores seguiram suas trajetórias políticas, como nos sugere a documentação, em âmbito local e, no caso de Pinto Ribeiro, em uma dimensão imperial, haja vista sua nomeação para desembargador da Relação da Bahia em 1807. Certamente acreditaram que o lugar de provedor seria estratégico para seus objetivos. Homens importantes, que estiveram envolvidos com a administração do império português em sua mais profunda essência, presentes na Câmara e/ou na Santa Casa, conforme o provérbio alentejano.

\section{Considerações finais}

A bibliografia acerca do estudo da assistência durante a época moderna é unânime em demonstrar as complexas estruturas erguidas pelas sociedades para a assistência à pobreza. O século XVIII significou um recrudescimento dessa complexidade. À medida que as transformações operadas nos meios de produção e nas mentalidades provocavam a aceleração da economia em larga escala, a ascensão das burguesias às instâncias políticas e, como consequência desse processo conjunto, o aumento generalizado da pobreza, a busca por estratégias que amenizassem o furor social desse processo e garantissem o "avanço civilizatório" da humanidade se intensificou. É inegável, portanto, o impacto das novas ideias e do grande movimento humano operado na Europa e no mundo colonial sobre as configurações tradicionais da sociedade que eram então abandonadas, e com a assistência à pobreza não foi diferente. ${ }^{6}$

Em vista disso, o panorama analisado neste artigo nos revela indícios de que essas transformações adquiriram contornos bastante específicos para o universo social, político e 
cultural do império português. Ainda que as reformas planejadas pelo marquês de Pombal durante seu ministério e por alguns de seus seguidores, como Pina Manique, tenham indicado caminhos para alguma modernização, nos moldes da época, do aparato burocrático e administrativo lusoimperial, traços tardomedievais persistiram naquela sociedade.

A fundação da Santa Casa de Misericórdia de Campos dos Goytacazes está inserida nesse contexto. À constatação dos povos sobre a necessidade social de assistência aos mais carentes - fato que, àquela altura, estava impregnado do discurso higienista e de modernização das instituições - associaram-se costumes e práticas comuns às sociedades de Antigo Regime e que ditavam etiquetas e hierarquias há séculos.

Ao problematizar tal hibridismo nas dinâmicas sociais, não pretendo afirmar a ausência de relações entre a fundação da instituição estudada e a preocupação com a rápida propagação da pobreza na Paraíba do Sul do final dos Setecentos, conforme contextualizado. O desenvolvimento do comércio e o intenso fluxo humano nos caminhos para o Rio de Janeiro e para o Espírito Santo provocaram um aumento populacional na região, alterando as bases das relações mercantis e de poder. O outro viés do desenvolvimento urbano das cidades é o aumento da pobreza. Tal panorama chamou a atenção das elites locais, que buscaram, a partir de então, estratégias para conter e amenizar esses influxos: a instituição da Santa Casa e, a partir daí, a fundação do cemitério e do hospital são indícios disso.

Acrescento, por fim, que em terras de conquistas, tal perspectiva ganhou dimensões incomensuráveis. O estabelecimento de vínculos estratégicos que garantiriam sobrevivência política e social a homens ocupantes de posições importantes na conjuntura do império, ainda que em suas localidades, atendeu à dinâmica de alargamento das referências simbólicas em fins de Antigo Regime.

\section{NOTAS}

${ }^{1}$ Sobre as relações de poder entre as Misericórdias e a Coroa portuguesa, Laurinda Abreu afirmou que, embora
o assunto seja deveras controverso entre os historiadores, "a iniciativa da ingerência nas Misericórdias
coube ao rei, quando poucas vezes assim terá acontecido". As diversas "facções opostas" em que se dividiam
os confrades retratavam muito bem, segundo a autora, a busca por estratégias de ascensão social e por
privilégios, levando-as a acordos tácitos que tornaram esses homens os "principais aliados da coroa, quer
delatando as irregularidades, quer mesmo apelando diretamente à mediação dos tribunais régios para
resolverem os conflitos que criavam ... A Coroa interveio sempre que tomava conhecimento dos desvios,
dos desregramentos e das fraudes" (Abreu, 2014, p.101). ${ }^{2}$ Sobre os conflitos na referida capitania, ver, além da obra de Alberto Lamego (1913-1943), Feydit (1979); mais recentemente, Atallah (2017b, 2018).

${ }^{3}$ Aproprio-me aqui da ideia de conquistadores discutida por João Fragoso (2001, p.36).

${ }^{4} \mathrm{O}$ conceito de redes clientelares adquire grande importância para a análise aqui desenvolvida. Baseia-se em uma "reflexão que procura desvendar os níveis menos evidentes das 'razões políticas'”. Durante o Antigo Regime, as "relações que obedeciam a uma lógica clientelar, como a obrigatoriedade de conceder mercês aos 'mais amigos', eram situações sociais cotidianas e corporizavam a natureza mesma das estruturas sociais, sendo, portanto, vistas como a 'norma"' (Xavier, Hespanha, 1994, p.381).

${ }^{5}$ A leitura de bacharel consistia em uma investigação feita pelo Desembargo do Paço sobre a ascendência do candidato a oficial da justiça, formado em leis ou cânones pela Universidade de Coimbra. Segundo José Subtil (1996, p.298), "constituiu um instrumento de controle e disciplina da magistratura territorial por se tornar indispensável no acesso à carreira".

${ }^{6}$ Para um estudo sobre as misericórdias no Império português ver, além dos já citados trabalhos, Gandelman (2005), Abreu (2014) e Franco (2014). 


\section{REFERÊNCIAS}

ABREU, Laurinda.

O poder e os pobres: as dinâmicas políticas e sociais da pobreza e da assistência em Portugal (séculos XVI-XVIII). Lisboa: Gradiva. 2014.

ABREU, Laurinda.

Pina Manique: um reformador no Portugal das Luzes. Lisboa: Gradiva. 2013.

ATA...

Ata da Câmara da Vila de São Salvador. Atas da Câmara Municipal de Campos dos Goytacazes 1811-1829. (Arquivo da Câmara Municipal de Campos dos Goytacazes). 5 abr. 1812.

ATA...

Ata da câmara de São Salvador, 1736. In: Feydit, Júlio. Subsídios para a história de Campos dos Goitacazes. Rio de Janeiro: Ésquilo. 1979a.

ATA...

Ata da primeira sessão da Irmandade Mãe dos Homens, 25 de julho de 1790. In: Feydit, Júlio. Subsídios para a história de Campos dos Goitacazes. Rio de Janeiro: Ésquilo. 1979b.

ATALLAH, Claudia C.A.

Entre a cruz e a caldeirinha: um ouvidor a serviço da monarquia nas terras dos Asseca. Tempo, v.24. n.1, p.161-179. Disponível em: <http://dx.doi.org/10.1590/tem-1980542x2018v240109>. Acesso em: 20 jun. 2018. 2018.

ATALLAH, Claudia C.A.

A Capitania da Paraíba do Sul Campos dos Goytacazes: o poder local, os ouvidores e suas jurisdições (1748-1753). In: Furtado, Junia Ferreira.; Atallah, Claudia C.A.; Santos, Patrícia Ferreira dos S.S. (Org.). Justiça, governo e bem comum na administração dos Impérios Ibéricos de Antigo Regime (séculos XV-XVIII). Curitiba: Prismas. 2017a.

ATALLAH, Claudia C.A.

A administração da justiça nas terras dos Asseca: uma análise da carta de doação da Paraíba do Sul dos Campos dos Goytacazes (1674-1727). In: Bicalho, Maria F.; Assis, Virgínia Maria A. de; Mello, Isabele de M. Pereira. Justiça no Brasil colonial agentes e práticas. São Paulo: Alameda. p.257-279. 2017b.

ATESTADO...

Atestado do cirurgião-mor do Terço da Infantaria e Cavalaria Auxiliar dos Campos, 20 de julho de 1793. In: Lamego, Alberto. $A$ terra goitacá: a luz de documentos inéditos. Rio de Janeiro: Livraria Garnier. t.2. 1913-1943a.
ATESTADO...

Atestado passado em 28 e 29 de agosto de 1790 pelos ditos escrivão da vara e promotor do juízo eclesiástico da vila de São Salvador. In: Lamego, Alberto. A terra goitacá: à luz de documentos inéditos. Rio de Janeiro: Livraria Garnier. t.2. 1913-1943b.

BICALHO, Maria F.

A cidade e o Império o Rio de Janeiro no século XVIII. Rio de Janeiro: Civilização Brasileira. 2003.

BOSCHI, Caio.

A religiosidade laica. In: Bethencourt, Francisco; Chaudhuri, Kirt. História da expansão portuguesa. v.2. Navarra: Círculo de Leitores. p.419-428. 1998.

BOSCHI, Caio C.

Os leigos e o poder: irmandades leigas e política colonizadora em Minas Gerais. São Paulo: Ática. 1986.

BOXER, Charles.

Salvador Correia de Sá e a luta pelo Brasil e Angola, 1602-1686. São Paulo: Cia. Editora Nacional. 1973.

BOXER, Charles.

O império colonial português, 1415-1825. Lisboa:

Edições 70. 1969.

CARTA...

Carta ao governador do Rio de Janeiro. Rio de Janeiro Avulsos (1614-1830), caixa 157, doc. 11868 (Biblioteca Nacional Digital-Brasil, Projeto Resgate). 1796.

CARTA...

Carta do vice-rei conde de Rezende ao tenente coronel José Thomaz Brum, 1791. In: Martins, Fernando J. História do descobrimento e povoação da cidade de São João da Barra e dos Campos dos Goytacazes antiga capitania da Paraíba do Sul e da causa e origem do levante denominado dos Fidalgos. Rio de Janeiro: Typographia de Quirino \& Irmão. 1868.

CERTIDÃO...

Certidão passada pelo capitão Bento José Rabello. Vila de São Salvador. In: Lamego, Alberto. A terra goitacá: à luz de documentos inéditos. Rio de Janeiro: Livraria Garnier. t.2. 1913-1943.

DUBY, Georges.

As três ordens ou o imaginário do feudalismo.

Lisboa: Estampa. 1994.

FARIA, Sheila de C.

A colônia em movimento. Fortuna e família no cotidiano colonial. Rio de Janeiro: Nova Fronteira. 1998. 
FEYDIT, Júlio.

Subsídios para a história dos Campos dos Goitacazes. Rio de Janeiro: Ésquilo. 1979.

FRAGOSO, João.

A formação da economia colonial no Rio de Janeiro e de sua primeira elite senhorial (séculos XVI e XVII). In: Fragoso, João; Bicalho, Maria F.; Gouvêa, M. de Fátima (Org.). O Antigo Regime nos Trópicos: a dinâmica imperial portuguesa (séculos XVI-XVIII). Rio de Janeiro: Civilização Brasileira. p.29-73. 2001.

FRAGOSO, João.

Homens de grossa aventura: acumulação e hierarquia na praça mercantil do Rio de Janeiro, 1790-1830. Rio de Janeiro: Civilização Brasileira. 1992.

FRANCO, Renato J.

O modelo luso de assistência e a dinâmica das Santas Casas de Misericórdia na América portuguesa. Estudos Históricos, v.27, n.53, p.5-25. 2014.

FRANCO, Renato.

Pobreza e caridade leiga as Santas Casas de Misericórdia na América portuguesa. Tese

(Doutorado) - Universidade Federal Fluminense, Niterói. 2011.

GANDELMAN, Luciana M.

Mulheres para um império: órfãs e caridade nos recolhimentos femininos da Santa Casa da Misericórdia (Salvador, Rio de Janeiro e Porto - século XVIII). Tese (Doutorado em História) Universidade Estadual de Campinas, Campinas. 2005.

GONÇALVES, Jussemar W.

A Revolução Francesa e a invenção social da pobreza. Biblos, Rio Grande, v.23, n.1, p.9-24. Disponível em $<$ http://repositorio.furg.br/ handle/1/320>. Acesso em: 25 jun. 2009. 2009.

GOUVÊA, Maria de F.

Redes governativas portuguesas e centralidades régias no mundo português, c. 1680-1730. In: Fragoso, João; Gouvêa, Maria de F. (Org.). Na trama das redes: política e negócios no império português, séculos XVI-XVIII. Rio de Janeiro: Civilização Brasileira. p.155-179. 2010.

KARASCH, Mary.

Construindo comunidades: as irmandades dos pretos e pardos. História Revista, v.15, n.2. Disponível em: <https://www.revistas.ufg.br/ historia/article/view/14128>. Acesso em: 25 jun. 2018. 2010.

LAMEGO, Alberto.

História da Santa Casa de Campos. Rio de Janeiro: Edição do autor para a Santa Casa de Campos. 1951.
LAMEGO, Alberto.

A terra goitacá à luz de documentos inéditos. t.2. Rio de Janeiro: Livraria Garnier. 1913-1943.

LARA, Silvia H.

Senhores de régia jurisdição: o particular e o público na vila de São Salvador dos Campos dos Goitacases na segunda metade do século XVIII. In: Lara, Silvia. H.; Mendonça, Joseli M.N. Direitos e Justiças no Brasil. Campinas: Editora da Unicamp. p.59-99. 2006.

LEITURA...

[Leitura de Bacharel], Letra J, MÇ. 53, doc. 23. (Arquivo Nacional da Torre do Tombo, Lisboa). 1783.

LOPES, Maria Antónia Lopes.

As Misericórdias de D. José ao final do século XX. In: Portugaliea Monumenta Misericordiariun - Fazer a História das Misercórdias. v.1. Ed. lit. Centro de Estudos de História Religiosa da Universidade Católica Portuguesa; coord. científico José Pedro Paiva. Lisboa: União das Misericórdias Portuguesas. 2002.

OFÍCIO...

Ofício do capitão Mós das Ordenanças da vila de São Salvador dos Campos dos Goytacazes José Francisco da Cruz. Rio de Janeiro Avulsos (1614-1830), caixa 173, doc. 12787 (Biblioteca Nacional Digital-Brasil, Projeto Resgate). 1799.

OFÍCIO...

Ofício do conde de Resende a D. Rodrigo de Sousa Coutinho. Rio de Janeiro Avulsos (1614-1830), caixa 183, doc. 13370 (Biblioteca Nacional Digital-Brasil, Projeto Resgate). 1800.

MONTEIRO, Nuno G.

Os poderes locais no Antigo Regime. In: Monteiro, Nuno G.; Oliveira, César (Org.). História dos municípios e do poder local. Lisboa: Círculo de Leitores. 1996.

OLIVEIRA, José T. de.

História do estado do Espírito Santo. Vitória: Fundação Cultural do Espírito Santo. 1975.

REIS, Manoel M. do Couto.

Manuscritos de Manoel Martins do Couto Reis 1785: descrição geográfica, política e cronográfica do distrito dos Campos dos Goytacazes. Campos dos Goytacazes: Fundação Cultural Jornalista Oswaldo Lima; Rio de Janeiro: Arquivo Público do Estado do Rio de Janeiro. 2011.

REPRESENTAÇÃO...

Representação de João Antônio de Moraes contra o ouvidor João Pinto Ribeiro. Bahia Eduardo de Castro Almeida (1613-1807), caixa 118, doc. 23199. (Biblioteca Nacional Digital-Brasil, Projeto Resgate). 1794. 


\section{REQUERIMENTO...}

Requerimento de Manoel Sebastião Vitorino da Silva e Melo à rainha. Rio de Janeiro Avulsos (1614-1830), caixa 128, doc. 10209 (Biblioteca Nacional Digital-Brasil, Projeto Resgate). 1796.

REQUERIMENTO...

Requerimento do mestre de campo do Terço e da Infantaria e Cavalaria Auxiliar da vila de São Salvador José Caetano de Barcelos Coutinho. Rio de Janeiro Avulsos (1614-1830), caixa 154, doc. 11709 (Biblioteca Nacional Digital-Brasil, Projeto Resgate). 1802.

\section{REQUERIMENTO...}

Requerimento do mestre de campo do Terço e da Infantaria e Cavalaria Auxiliar da vila de São Salvador José Caetano de Barcelos Coutinho. Rio de Janeiro Avulsos (1614-1830), caixa 197, doc. 13995 (Biblioteca Nacional Digital-Brasil, Projeto Resgate). 1801.

RUSSELL-WOOD, Anthony J.R.

Fidalgos e filantropos: a Santa Casa da

Misericórdia da Bahia, 1550-1755. Brasília:

Editora Universidade de Brasília. 1981.

SÁ, Isabel dos G.

As Misericórdias portuguesas séculos XVI a XVIII. Rio de Janeiro: FGV. 2013.

SÁ, Isabel dos G. e PAIVA, José P. Introdução. In: Portugalliae Monumenta Misericordiarium - A Fundação das Misericórdias: o Reinado de D. Manuel I. v.3. ed. lit. Centro de Estudos de História Religiosa da Faculdade de Teologia - Universidade Católica Portuguesa. Lisboa: União das Misericórdias Portuguesas. 2002.
SILVA, José C. da.

Memória Topographica e Histórica sobre os Campos dos Goitacazes com huma notícia breve de suas produções e comércio. Rio de Janeiro: Impressão Régia. 1819.

SOARES, Márcio de $\mathrm{S}$.

De pai para filho: legitimação de escravos, herança e ascensão social de forros nos Campos dos Goytacases, c.1750-c.1830. In: Quinto Congresso Brasileiro de História Econômica e sexta Conferência Internacional de História de Empresas. Belo Horizonte: ABPHE. 2003.

SUBTIL, José.

O Antigo Regime da saúde pública entre o Reino e o Brasil. Revista Ultramares, v.1, n.8. Disponível em: <https://sites.google.com/site/ revistaultramares/antigo-regime-da-saudepublica-entre-o-reino-e-o-brasil >. Acesso em: 25 jun. 2018. 2015.

SUBTIL, José.

O direito de polícia nas vésperas do Estado liberal em Portugal. In: Fonseca, Ricardo M. (Coord.). As formas do direito, ordem, razão $e$ decisão: experiências jurídicas antes e depois da Modernidade. Curitiba: Juruá. p.275-332. 2013.

SUBTIL, José.

Dicionário dos Desembargadores (1640-1834).

Lisboa: Ediual. 2010.

SUBTIL, José M. Lousada.

O Desembargo do Paço (1750-1833).

Departamento de Ciências Humanas. Lisboa: Universidade Autónoma de Lisboa. 1996.

XAVIER, Ângela Barreto; HESPANHA, António. M. As redes clientelares. In: Hespanha, António M. (Coord.). História de Portugal. v.4. Lisboa: Estampa. 1994. 